Nevşehir Bilim ve Teknoloji Dergisi Cilt 6(2) 633-642 2017

DOI: 10.17100/nevbiltek.306207

URL: http://dx.doi.org/10.17100/nevbiltek.306207

\title{
Fotovoltaik Panel ile Beslenen Adım Motorunun PIC Denetleyici Kullanarak Adım Açısının Kontrol Tasarım ve Uygulaması
}

\author{
Ayşe KOCALMIŞ BILLHAN* \\ Nevşehir Üniversitesi, Mühendislik ve Mimarlık Fakültesi, Elektrik Elektronik Mühendisliği Bölümü, \\ Nevşehir \\ $\ddot{O} \mathbf{z}$ \\ Son yıllarda, adım motorları başta elektronik ve bilgisayar teknolojileri olmak üzere hassas konum kontrolü gerektiren birçok \\ uygulamada kullanılmaktadır. Bu çalışmada, adım motor kullanılan farklı özelliklerdeki mekanik sistem uygulamaları için bir \\ denetleyici tasarlanmıştır. Çalışma sırasında, besleme gerilimi olarak günümüzde popülaritesi gün geçtikçe artan temiz enerji \\ kaynaklarının başında yer alan Fotovoltaik (FV) panel tercih edilmiştir. Ayrıca çıkış gerilimi değerini sabitlemek, Fotovoltaik \\ panele gelen güneş ışınlarının sebep olduğu panel çıkışındaki gerilim dalgalanmalarının önüne geçmek ve sisteme bağlı olan akünün \\ ihtiyacı olan gerilim değerini elde edebilmek için şarj kontrol regülatörü kullanıldı. Bu makale permanent mıknatıslı adım motorun \\ PIC16F84A olarak bir mikrokontrolör kullanılarak kontrol edilmesine odaklanmıştır. Önerilen sistem Proteus programı ile benzetim \\ modeli gerçekleştirilmiş ve kontrol devresi ile deneysel bir sistem üzerinde test edilmiştir.
}

Anahtar Kelimeler: Adım motor, Kontrolör, Fotovoltaik sistem

\section{Design and Implementation of Step Angle Control by using PIC Controller for Step Motor-Fed Photovoltaic Panels}

\begin{abstract}
In recent years, stepper motors have been used in many applications such as requiring precise position control, primarily electronic and computer technology. In this work, the controller is designed for mechanical system applications in different specifications using stepping motors. During the study, photovoltaic (PV) panel, which is at the head of the clean energy sources which are increasing in popularity today as the supply voltage, is preferred. In addition, the charge control regulator was used to stabilize the output voltage, to prevent voltage fluctuations at the panel output caused by solar radiation from the photovoltaic panel and to obtain the voltage value of battery which is connected to the system. This article focuses on controlling the permanent magnet stepper motor as a PIC16F84A using a microcontroller. The proposed system was simulated with the Proteus program and tested on an experimental system with a control circuit.
\end{abstract}

Keywords: Step motor, Controller, Photovoltaic system

\footnotetext{
*e-mail: akbilhan@nevsehir.edu.tr
} 


\section{Giriş}

Günümüzde hızlı sanayileşme ve teknolojinin sürekli gelişmesi ile enerjiye ve dolayısıyla enerji kaynaklarına olan ihtiyaç gün geçtikçe artmaktadır [1-4]. Fosil yakılar olarak nitelendirilen kömür, linyit gibi enerji kaynaklarının tükenecek olması ve daha önemlisi bu kaynakların kontrolsüz ve denetimsiz kullanımları sonucu açığa çıkan sera gazlarının ve atıklarının çevrede meydana getirdikleri zararlar, araştırmacıları; alternatif enerji kaynaklarının araştırılması ve kullanımlarının yaygınlaştııılması konularına yönlendirmektedir [5-7]. Bu alternatif enerji kaynakları; su gücünden yararlanılan hidroelektrik santraller (HES), yeraltı kaynaklarından jeotermal enerji, rüzgâr gücünden yararlanılan rüzgâr türbinleri, güneş enerjisinden yararlanılan güneş panelleri yada nükleer enerjiden yararlanılan nükleer santraller vb. olarak sıralanabilir [8]. HES'lerin kurulum maliyetlerinin oldukça yüksek olması ve tarım arazilerine zarar vermeleri, jeotermal enerjinin sınırlı olması, rüzgar enerjisinin iklime bağlı olması ve her alanda elde edilememesi, nükleer enerjinin ise kurulum aşamasından üretim aşamasına kadar güvenlik sorunlarından dolayı güneş enerjisinin kullanıldığı güneş panel/santralleri günümüzde en çok tercih edilen alternatif enerji kaynaklarının başında gelmektedir. Son yıllarda, çevre kirliliği, küresel 1sınma, enerji güvenliği, teknolojik iyileştirmeler ve maliyetlerinin düşürülmesi endişeleri nedeniyle Fotovoltaik (FV) enerji üretim sistemlerinin kurulması gün geçtikçe artmaktadır [9,10]. Günümüzde, FV üretim sistemleri, temiz ve çevre dostu bir enerji kaynağı olarak kabul edilir. Özellikle FV kullanılarak üretilen enerjinin atmosferde herhangi bir kirlilik yapmaması, FV üretim sisteminin sessiz çalışması ve üretim sisteminin enerji kaynağının sonsuz ve ücretsiz olan güneş enerjisi olmasından dolayı FV üretim sistemleri oldukça popüler bir hale gelmektedirler. Genel olarak bağımsız (tek başına çalışan-şebekeden bağımsız) veya şebekeye bağlı olarak iki tip yapılandırılmaları bulunmaktadır. Şebekeden bağımsız FV üretim sistemleri, uzak bölgeler için vazgeçilmez elektrik kaynağı olduğu için oldukça caziptir [11]. Ancak FV üretim sistemlerinin de belirli iki önemli sorunu vardır; düşük ışınlama koşullarında düşük dönüşüm enerjisi sahiptirler ve üretilen elektrik enerjisinin miktarı, hava koşullarıyla sürekli değişir.

Adım motorları genel olarak belirli bir artış ile hareket eden motorlardır [12]. Bir adım motoruna, tasarlanan bir kontrolör tarafindan üretilen kare dalga darbe uygulanır ve karşıllı̆ında rotor her bir darbe için belirlenen açı kadar hareket eder. Son yıllarda; güç elektroniği elemanları, devreleri ve elektrik makinalarında oldukça fazla gelişme olsa bile, adım motorları, yaygın olarak birçok alanda kullanmaya devam edilmektedir. Özellikle hareket kontrol sistemleri, robot uygulamaları, uzay uygulamaları ve daha birçok değişik alanlardaki uygulamalarda adım motorları tercih edilmektedir. Bunun en temel sebebi ise oldukça ucuz olan adım motorlarının, basit bir yapıya sahip olmaları ve dijital elektronik devreler ile uyumlu çalışabilmeleridir. Ayrıca firça ve kollektöre sahip olmamaları da bir başka avantajlarıdır. Bu nedenle kirlenme problemleri ve bakım gereksinimleri yoktur.

Ancak bu avantajlarının yanı sıra, yük momentinden ve ataletten etkilenerek yüksek hızlarda hız kaybı meydana gelebilmektedir. Ayrıca sabit adım açılarının rotora uygulanması ile hareket sağlandığından, hareket sürekli değil de darbelidir. Bu dezavantajlarına ek olarak da çıkış güçleri ve momentleri sınırlidır.

Adım motorlarında, motora 900, 450, 180, 7.50 vb. ile uygulanacak adım açısı ile rotorun hareket etmesi sağlanır. Motora uygulanan sinyallerin frekansı değiştirilerek motorun hızı da kontrol 
edilebilir. Aynı zamanda bu sinyallerin sırası değiştirilirse step motorlarının dönüş yönü, saat ibresi yönünde $(\mathrm{CW})$ veya saat ibresinin tersi yönünde $(\mathrm{CCW})$ olabilir.

$\mathrm{Bu}$ çalışmada, küçük boyutlu bir Adım Motorun için hız/konum kontrolü modellenmiş ve deneysel devre çalışması gerçekleştirilmiştir. Ayrıca deneysel çalışma sırasında, giriş gerilimi küçük güçlü bir FV panelden karşılanarak şebekeden bağımsız çalışma gerçekleştirilmiştir.

\section{Fotovoltaik Benzetim Modeli}

Uzun yıllar içerinde yapılan çalışmalar ile birçok FV hücre modeli geliştirilmiştir. Bu çalışmada ise, bir akım kaynağına paralel bağlı bir diyot ve direnç ile seri bağlı bir dirençten meydana gelen devre yapısı kullanılacaktır $[13,14]$. Şekil 1 ile bu yapı gösterilmektedir. G ışınmayı ve T mutlak sıcaklığı göstermektedir. $R_{s}$ metal bağlantı noktaları ve yarı iletken maddeden oluşan devre yolunun toplam direncini, $\mathrm{R}_{\mathrm{p}}$ ise kaçak akımı ifade etmektedir. Bu durumda tek bir $\mathrm{FV}$ hücre için çıkış gerilimi $\left(\mathrm{V}_{\mathrm{FV}}\right)$ ve çıkış akım değeri $\left(\mathrm{I}_{\mathrm{Fv}}\right)$ Denklem 1 ve 2 ile hesaplanabilir.

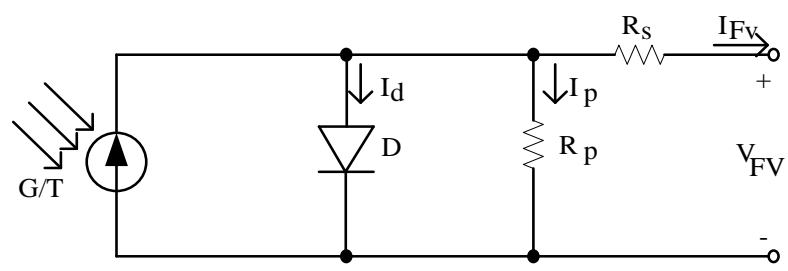

Şekil 1. Fotovoltaik (FV) Hücre Modeli

$$
\begin{gathered}
\mathrm{I}_{\mathrm{FV}}=\mathrm{I}_{\mathrm{ph}}-\mathrm{I}_{\mathrm{o}^{\prime}}\left[\exp \left(\frac{\mathrm{q}\left(\mathrm{V}_{\mathrm{FV}}+\mathrm{I}_{\mathrm{FV}} \mathrm{R}_{\mathrm{g}}\right)}{\mathrm{NKT}}\right)\right]-\frac{\mathrm{V}_{\mathrm{FV}}+\mathrm{I}_{\mathrm{FV}} \mathrm{R}_{\mathrm{s}}}{\mathrm{R}_{\mathrm{p}}} \\
V_{\mathrm{FV}}=\frac{\mathrm{NKT}}{\mathrm{q}}\left[\frac{\mathrm{I}_{\mathrm{ph}}+\mathrm{I}_{\mathrm{d}}-\mathrm{I}_{\mathrm{FV}}}{\mathrm{I}_{\mathrm{FV}}}\right]-\mathrm{R}_{\mathrm{g}} \mathrm{I}_{\mathrm{FV}}
\end{gathered}
$$

Bu denklemlerde kullanılan, $\mathrm{I}_{\mathrm{ph}}$; fotoakımı $(\mathrm{A}), \mathrm{I}_{\mathrm{o}}$; saturasyon akımını, q; değeri $1.6 \times 10^{-19}$ olan elektron yükünü, $\mathrm{K}$; değeri $1.38 \times 10^{-23} \mathrm{j} /{ }^{\circ} \mathrm{K}$ olan Boltzman sabitini, $\mathrm{T}$; Kelvin cinsinden mutlak hücre sıcaklı̆̆ını $\left(273,15+{ }^{\circ} \mathrm{C}\right), \mathrm{I}_{\mathrm{d}}$; diyotun ters doyma akımını ve $\mathrm{N}$; eğri uydurma faktörünü göstermektedir.

FV pilleri, belirli güneşlenme şartlarında, birim alan başına belirli bir akım ve voltaj üretirler. Ancak sadece bir FV hücreden elde edilebilecek yaklaşık gerilim değeri $0.5 \mathrm{~V}$ civarındadır. Bu nedenle, arzu edilen enerjiye ulaşmak için birçok pili seri $\left(\mathrm{N}_{\mathrm{s}}\right.$ adet) ve paralel $\left(\mathrm{N}_{\mathrm{p}}\right.$ adet $)$ olarak bağlamak gerekir. Bir her bir kolda seri olarak $\mathrm{N}_{\mathrm{s}}$ adet $\mathrm{FV}$ hücrenin bulunduğu, $\mathrm{N}_{\mathrm{p}}$ adet paralel bağlanmış $\mathrm{FV}$ modül çıkış gerilim ve akımı Denklem 3 ve 4 ile hesaplanır. Burada $V_{\mathrm{FVT}}$ ile FV modül çıkış gerilimi ve $\mathrm{I}_{\mathrm{FVT}}$ ile FV modül akımı gösterilmektedir $[8,15]$. Şekil 2 ile bir FV pil için tipik akım-gerilim (I-V) dalga şekli gösterilmektedir.

$$
\begin{aligned}
& V_{F V T}=N_{g} V_{F V} \\
& I_{F V T}=N_{p V} I_{F V}
\end{aligned}
$$




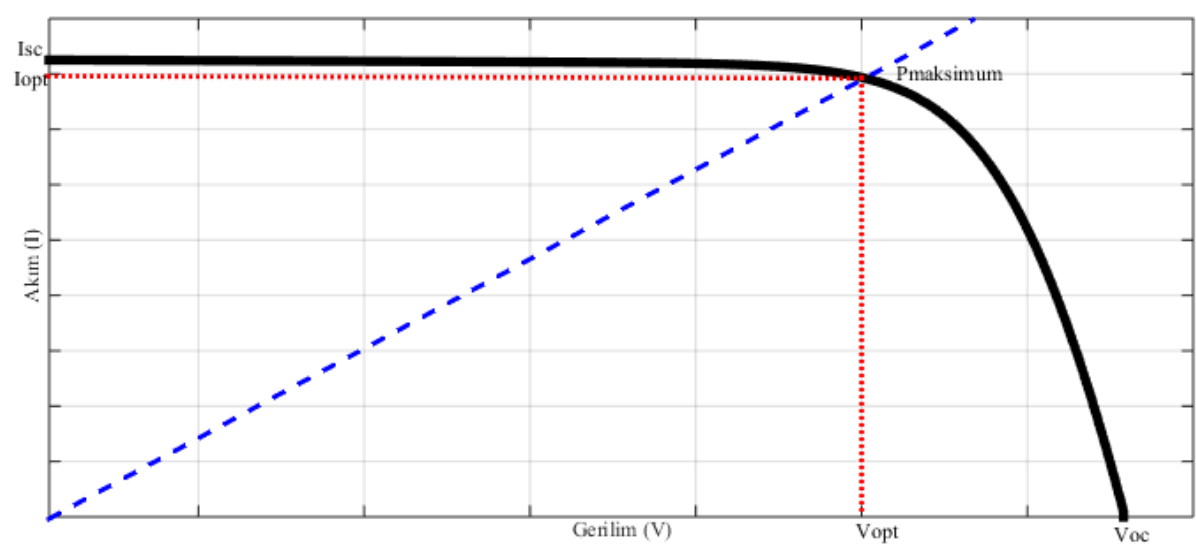

Şekil 2. Fotovoltaik (FV) Hücreye ait IV Karakteristiği

Şekil 2 ile gösterilen Akım-Gerilim (I-V) karakteristiğinde; $V_{\text {oc }}$ açık devre gerilim değerini, $I_{\mathrm{sc}}$ kısa devre akım değerini, $V_{\text {opt }}$ ve $\mathrm{I}_{\text {opt }}$ optimum çalışma noktasında sırasıyla akım ve gerilim değerlerini göstermektedir. $P_{\text {maksimum }}$ ise yüke aktarılan gücün maksimum olduğu işaret etmektedir.

\section{Adım Motorları}

Adım motorlar makinanın yapısına ve çalışmasına göre sınıflandırılmaktadırlar. En önemli Adım motorları; Sabit Mıknatıslı, Değişken Relüktanslı ve Hibrid adım motorlarıdır. Diğer tür adım motorlar, bu üç tip adım motorların varyasyonları olarak geliştirilen Hidrolik adım motorları ve Lineer adım motorlarıdır [16]. Bir adım motorunu hızını; mekanik derece, elektriksel ve mekanik hız olarak hesaplayabilir. Denklem 5 ile her bir devir için dakikadaki devir ve dakikadaki darbe sayısına karşıllık motor hızının hesaplanması gösterilmektedir. $\mathrm{n}_{\text {darbe }}$ ise dakikadaki darbe sayısını, P kutup sayısını göstermektedir [17].

$$
\mathrm{n}_{\mathrm{m}}=\frac{1}{3 \mathrm{P}} \mathrm{n}_{\mathrm{darbe}}
$$

\subsection{Sabit Mıknatıslı Adım Motorları}

Sabit mıknatıslı adım motorlarında (pernanent magnet stepper motor), stator üzerinde uyarma bobini taşıyan kutuplar vardır. Sabit mıknatıslı kademeli motorlarda moment, stator akımları ve mıknatıslar tarafından oluşturulan rotor akısının etkileşimiyle üretilen elektromanyetik momenttir. Şekil 3 ile sabit mıknatıslı adım motoru gösterilmektedir.

Şekil 3'de gösterilen yapıdan iki kutuplu sabit mıknatıslı rotor 4 kutuplu stator içerisinde dönerek hareket etmektedir ve görüldüğü gibi adım açısı $90^{\circ}$ 'dir. Sabit mıknatıslı adım motorların momenti diğer adım motor çeşitlerine göre oldukça düşüktür. Ayrıca rezonansa eğilimli olmalarından dolayı kullanım alanları sınırıdır. Bu çeşit adım motorları oldukça düşük hareket süresi gerektiren kontrol sistemlerinde kullanılırlar [18]. 


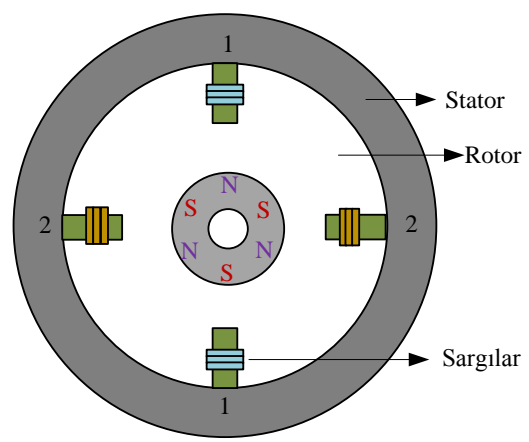

Şekil 3. Sabit mıknatıslı adım motorları

\subsection{Değişken Relüktanslı Adım Motoru}

Değişken relüktanslı adım motorları, sabit mıknatıslı adım motorlarının aksine rotorları dişli yapıda olan motorlardır. Şekil 4 ile üç fazlı değişken relüktanslı adım motorunun yapısı gösterilmektedir. Bu yapıda rotor kutuplu ve stator ise 6 adet dişliye sahiptir.

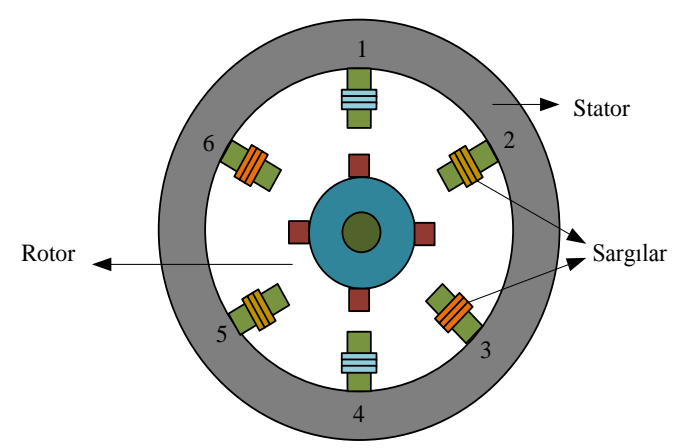

Şekil 4. Değişken Relüktanslı Step Motor

Değişken relüktanslı adım motorlarında daha yüksek moment değerine ulaşabilmek için stator ve rotor dişlileri arasındaki hava aralığının küçük tutulması gerekir. Ayrıca küçük rotora sahip olduklarından eylemsizlik momentleri de küçük olur ve rotorları daha çabuk hareketlenir.

\subsection{Hibrid Adım Motoru}

Hibrid adım motorları, hem değişken relüktanslı ve hem de sabit mıknatıslı motorların çalışma prensiplerini bir arada kullanan adım motorlarıdır. Rotorlarının dişli yapıda olmasının yanı sıra, stator üzerindeki kutuplarda dişlilere ek olarak sargılarda bulunmaktadır. Şekil 5 ile hibrid adım motoruna ait bir kesit gösterilmektedir.

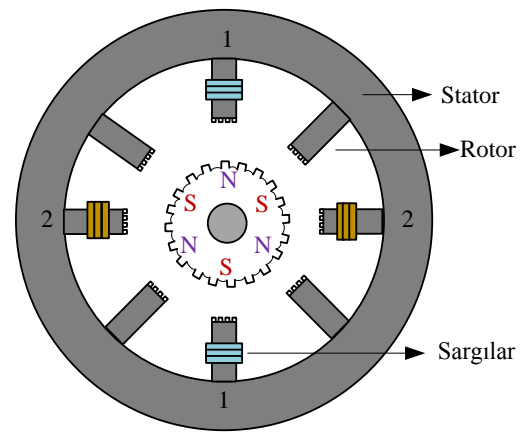

Şekil 5. Hibrit Step Motor 
Genel olarak bir hibrid adım motoru 8 stator kutbundan oluşur. Statora uygulanan sinyallerin düzgün sıralanmasıyla adım hareketi gerçekleştirilmiş olur.

\section{Benzetim Modeli ve Deneysel Sonuçlar}

Bu çalışmada, 10W'lık bir güneş paneli kullanılarak elde edilen enerji ile kurulacak deneysel çalışmanın enerji ihtiyacı karşılanacaktır. Ancak güneş ışınlarının her zaman aynı açı ile gelmemesi ve ışınım değerinin değişiklik arz etmesi nedenleriyle, güneş paneli kullanılarak elde edilen enerjinin istenilen değere düşürülmesi ve regüle edilmesi gerekmektedir. Bu nedenle deneysel çalışma sırasında düşürücü (buck) Doğru Akım/Doğru Akım (DA/DA) çevirici devresi kullanılmaktadır. Ayrıca devrenin sürekli durum çalışmasını sağlamak amacıyla da, $6 \mathrm{~V}$ değerinde bir akü kullanılmaktadır.

Sürme devresinin kontrol sinyallerini oluşturmak için MPLAB programı kullanılarak yazılan program LEAPER48 PIC programlayıcısı ile PIC16F84A işlemcisine yüklendi. Ayrıca işlemcinin besleme gerilim değeri $5 \mathrm{~V}$ olduğu için, devrede kontrolü gerçekleştirilecek olan adım motoru olarak, besleme gerilim değeri $5 \mathrm{~V}$ olan sabit mıknatıslı adım motoru tercih edilmiştir. Adım motorunun dönüş yönünün dışarıdan belirlenmesi istenildiği yada durdurulması amaçlarıyla; sağa dönüş butonu, sola dönüş butonu ve durdurma butonları devre kullanılmıştır. Ayrıca adım motorunun çalışması sırasında dönüş yönünün daha rahat anlaşılabilmesi için de ledler kullanılmışır.

Deneysel çalışma tamamlanmadan önce devrenin benzetim modeli Proteus 8 kullanılarak test edildi. Bu çalışma Şekil 6 ile gösterilmektedir.

Şekil 6 ile gösterilen şemada adım motorunun sağ dönüşü esnasında kırmızı ledler, sola dönüşü esnasında ise yeşil ledler yanmaktadır. Ayrıca gerçekleştirilen program ile adım motorunun her iki yönde gerçekleştireceği tam adım hareketinde, dönüş yönü bağlı olarak hangi renk aktif (sadece kırmızı veya sadece yeşil) ise ikili olarak sürekli yanmakta, yarım adım hareketinde ise hangi renk aktif (sadece kırmızı veya sadece yeşil) ise tek bir tanesi yanmaktadır. Aynı sonuçlar deneysel çalışma sırasında da yerleştirilen ledler ile gözlemlenmektedir.

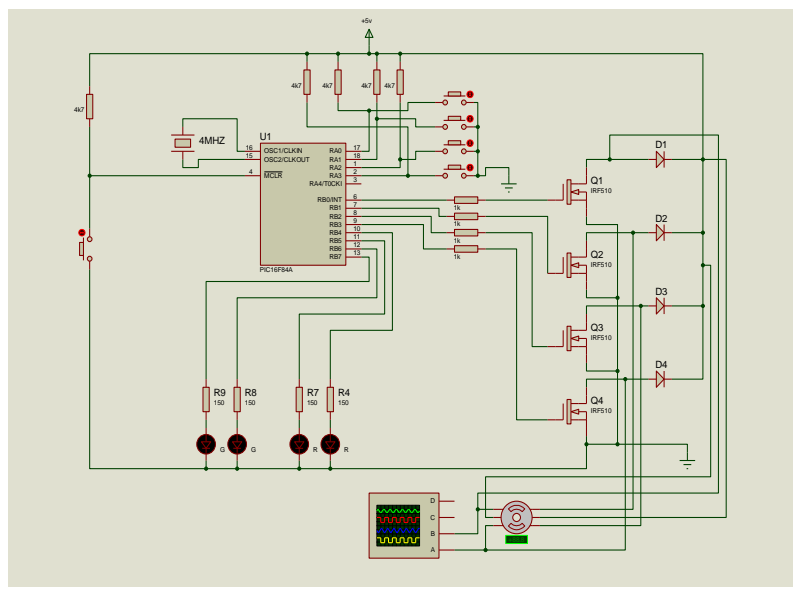

Şekil 6. Proteus programı kullanılarak benzetim modeli oluşturulan step motor kontrolü

Bilgisayar ortamında gerçekleştirilen benzetim modeline ait deneysel çalışma ise Şekil 7 ile gösterilmektedir. 


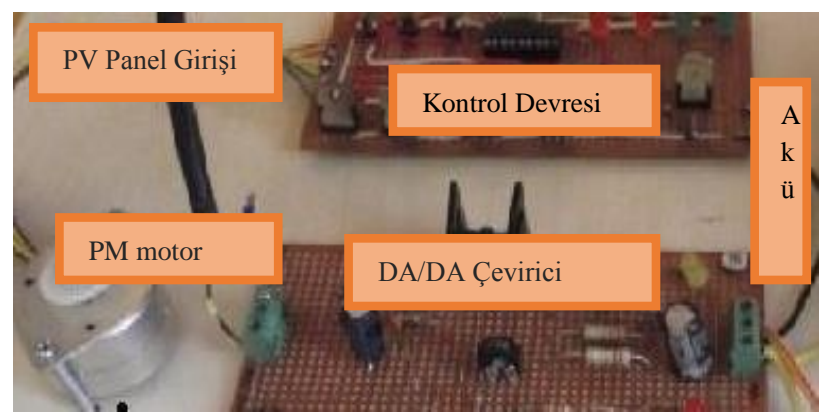

Şekil 7. PV Panel ile beslenen Adım motoru kontrol devresi

Devrenin enerji ihtiyacının karşılanması sırasında, üretici firma tarafından modül parametreleri standart test koşullarında $\left(1000 \mathrm{~W} / \mathrm{m} 2\right.$ güneş ışııımı ve $250^{\circ} \mathrm{C}$ PV modül sıcaklığı) verilen WE-10 FV paneli kullanılmaktadır. Monokristal yapıda olan bu panel ile gerekli ışınım altında $15 \mathrm{~V}$ ile $18 \mathrm{~V}$ arasında bir gerilim değeri elde edilmektedir. Panele ait özellikler Tablo 1 ile gösterilmektedir.

\begin{tabular}{lcl}
\multicolumn{3}{c}{ Tablo 1. WE-10 teknik özellikleri } \\
\hline Açık Devre Gerilimi & (Voc) & $21 \mathrm{~V}$ \\
Kısa Devre Akımı & (Isc) & $0.67 \mathrm{~A}$ \\
Maks. Güç Noktasındaki Gerilim & (Vmpp) & $17 \mathrm{~V}$ \\
Maks. Güç Noktasındaki Akım & (Impp) & $0.59 \mathrm{~A}$ \\
\hline
\end{tabular}

$\mathrm{Bu}$ çalışma sırasında kullanılan DA/DA çeviriciye uygulanan mevcut giriş gerilim değeri düşürülerek çıkışında daha düşük bir gerilim elde edilmesini sağladı. Bu sayede; hem PIC16F84A hem de adım motorunun çalıştırılması için gerekli olan 5V'luk gerilim değeri FV panel ile üretilerek kullanıldı. Ayrıca kullanılan bu yapı ile yeterli güneş ışınımı olduğu durumlarda, devrenin sürekli çalışmasıını sağlayacak bakımsız, kuru tip olan 6,3V 4 AH/20 özelliklerindeki akünün de şarj edilmesi gerçekleştirildi.

$\mathrm{Bu}$ çalışma sonucunda; sırasıyla step motorun sargılarına gönderilen sağa yarım adım dönüş, sağa tam adım dönüş, sola yarım adım dönüş ve sola tam adım dönüş sinyallerinin osiloskop görüntüleri, Şekil 8-11 ile gösterilmektedir.

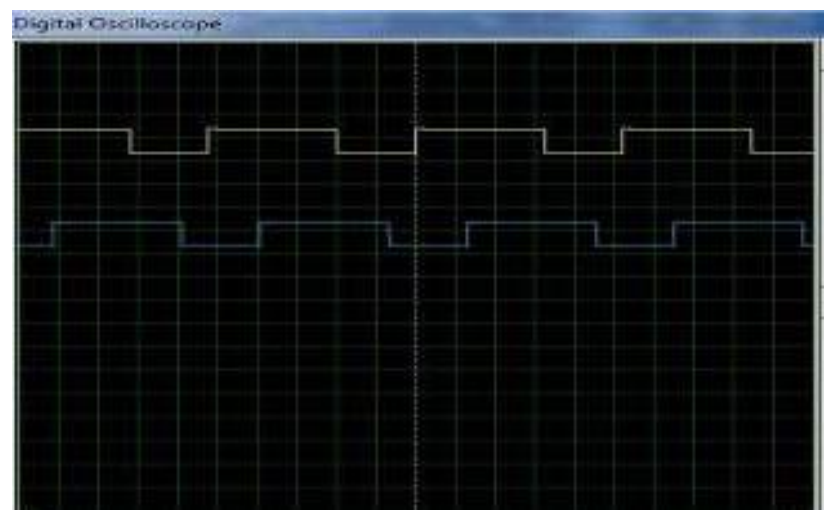

Şekil 8. Step motorun sağ yarım adım uyartım durumunda faz sargılarına uygulanan sinyaller 
Kocalmış Bilhan A.

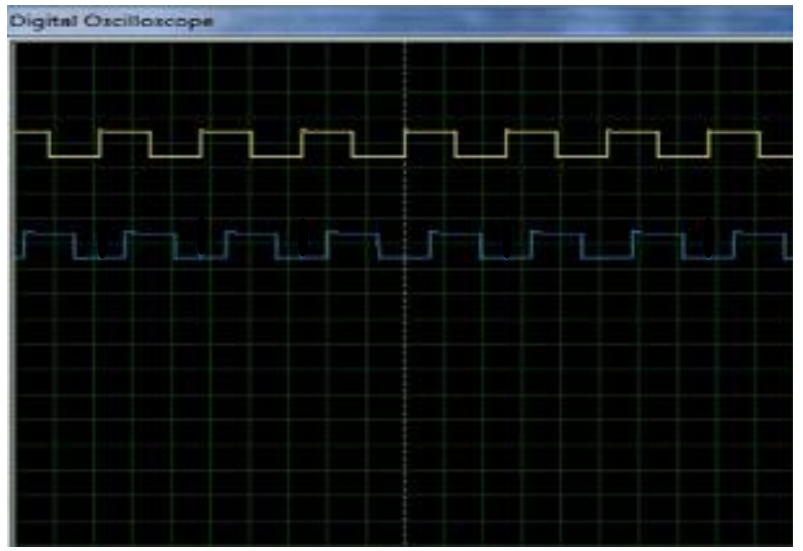

Şekil 9. Step motorun sağ tam adım uyartım durumunda faz sargılarına uygulanan sinyaller

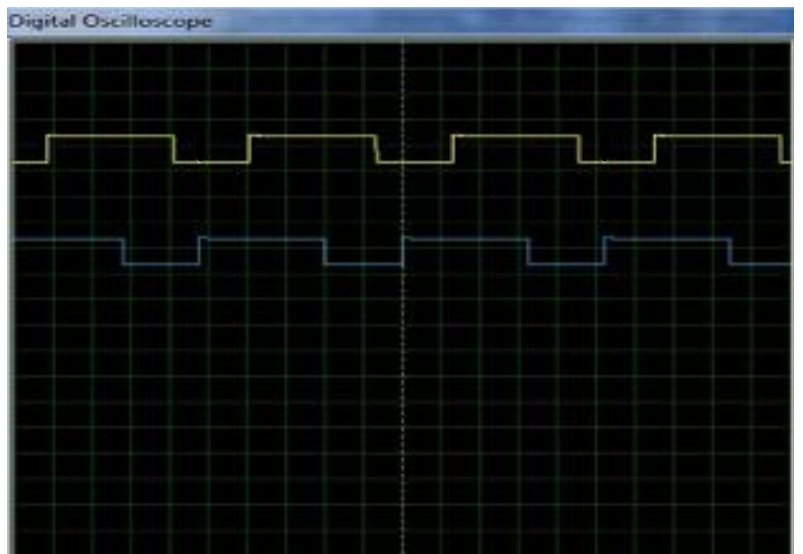

Şekil 10. Step motorun sol yarım adım uyartım durumunda faz sargılarına uygulanan sinyaller

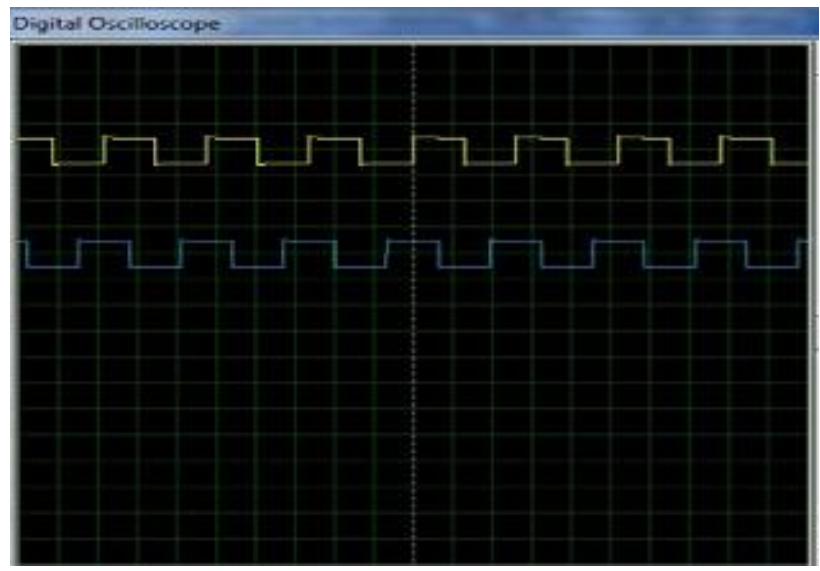

Şekil 11. Step motorun sol tam adım uyartım durumunda faz sargılarına uygulanan sinyaller

Yarım adım uyarıımı gerçekleştirmek için tek faz ve iki faz ard arda uygulanırken Şekil 8-11 arasında gösterilen sağ ve sol yönlerdeki yarım ve tam adım uyartımlar sırasında adım motoruna uygulanan darbelerin (pulse) sürelerinin değişimi gösterilmektedir. Ayrıca yarım adım uyartım durumunda darbe sürelerindeki bu değişimlerin hız üzerinde değişimlere sebep olduğu gözlenmiştir. 


\section{Tartışma ve Sonuç}

Teknolojinin gün geçtikçe önlenemez bir şekilde gelişimi, insan nüfusunun hızlı artışı enerjiye olan ihtiyacı sürekli artırmaktadır. Ancak artan bu ihtiyaçla beraber alternatif enerji kaynakları konularında yapılan çalışmalarda artmaktadır. Gerek kullanılan araçlarda gerek ise yaşam alanlarında giderek temiz enerji kaynaklarının kullanımı daha fazla tercih edilmeye başlamıştır. Alternatif enerji kaynaklarının kullanım alanlarının gün geçtikçe artmasının yanı sıra özellikle güç elektroniği elemanlarında meydana gelen gelişmeler birçok sistemin boyutlarının küçülmesine hassas konum hesabının gerektiği uygulamaların artmasına sebep olmaktadır. Bu sayılanlarla birlikte özellikle mikrokontrolörlerle kontrol işlemlerinin yapılabilmesi, geri beslemeye ihtiyaç duyulmaması ve üretim maliyetlerinin düşük olmalarından dolayı adım motorları robotikten araç endüstrisine, uzay araçlarından ev gereçlerinde kadar birçok alanda kullanım olanağına sahiptir. Bu nedenlerle bu çalışma sırasında adım motorları için, alternatif ve temiz enerji kaynaklarının başında gelen güneş enerjisinin kullanıldığı bir sistem tasarlanmış ve deneysel sonuçları elde edilmiştir.

Çalışma sırasında ilk olarak FV hücrenin matematiksel modelinden yararlanılarak MATLAB/Simulink ortamında benzetim modeli gerçekleştirilmiştir. Daha sonra adım motorunun kontrolü bir mikroişlemci ile ve enerji kaynağı ise bir FV panel kullanılarak tasarlandı. Yapılan bu çalışma ile tasarlanan sistem modüler hale getirilerek; robot teknolojisi, sulama sistemleri veya diğer endüstriyel alanlarda kullanılabilecektir.

\section{Teşekkür}

Bu çalışma sırasında NEÜBAP14F5 proje kapsamında verdikleri destekten dolayı Nevşehir Hacı Bektaş Veli Üniversitesi Bilimsel Araştırma Projeleri Birimi’ne teşekkürlerimi sunarım.

\section{Kaynaklar}

[1] Ahmedy T, Nishida K, Nakaoka MC. "Wind Power Grid Integration of an IPMSG Using a Diode Rectifier and a Simple MPPT Control for Grid-Side Inverters". Journal of Power Electronics, 10(5), 548-554, 2010.

[2] Carrasco JM, Franquelo LG, Bialasiewicz JT, Galvan E, Guisado RCP, Prats MAM, Leon JI, and Alfonso NM. "Power-electronic systems for the grid integration of renewable energy sources: a survey". IEEE Transactions on Industrial Electronics, 53(4), 1002-1016, 2006.

[3] Lee JE, Liang TJ, Chen JF. "Isolated coupled inductor integrated DC-DC converter with nondissipative snubber for solar energy applications". IEEE Transactions on Industrial Electronics, 61(7), 3337-3348, 2014.

[4] Cheng KWE, Sutanto D, Ho YL, Law KK. "Exploring the power conditioning system for fuel cell”. IEEE Power Electronics Specialists Conference, Vancouver, Canada, 2197-2202, 2001.

[5] Koutroulis E, Kalaitzakis K, Voulgaris NC. "Development of a Microcontroller-Based, Photovoltaic Maximum Power Point Tracking Control System”. IEEE Transactions on Power Electronics, 16(1), 46-54, 2001.

[6] Shicheng Z, Wei L. "Research and Implementation of Photovoltaic Charging System with Maximum Power Point Tracking”. International Conference on Industrial Engineering and Applications, Xi'an, China, 619-624, 2008. 
[7] Millman J, Halkias CC. Electronic Devices and Circuits, McGrow-Hill, New York, 1967.

[8] Altaş İH. "Yenilenebilir Enerji Kaynakları ve Türkiye deki Potansiyel". Enerji, Elektrik, Elektromekanik Dergisi, 45, 58-63, Şubat 1998.

[9] Pires VF, Martins JF, Foito D, Hão C. "A Grid Connected Photovoltaic System with a Multilevel Inverter and a Le-Blanc Transformer”. International Journal of Renewable Energy Research, 2(1), 84-91, 2012.

[10] Jain S, Ramulu C, Padmanaban S, Ojo JO, Ertas AH. "Dual MPPT Algorithm for Dual PV Source Fed Open-End Winding Induction Motor Drive for Pumping Application". An International Journal of Engineering Science and Technology, 19(4), 1731-1741, 2016.

[11] Philip J, et al. "Control and Implementation of a Standalone Solar Photo-Voltaic Hybrid System”. IEEE Transactions on Industrial Electronics, 52(4), 3472-3479, 2016.

[12] Bhag SG, Hiziroglu HR. Electric Machinery and Transformers. Oxford University Press., 2001.

[13] Ravi A, Manoharan PS, Anand JV. "Modeling and Simulation of Three Phase Multilevel Inverter for Grid Connected Photovoltaic Systems”. Solar Energy, 85, 2811-2818, 2011.

[14] Xiao W, Dunford WG, Capel A. "A Novel Modeling Method for Photovoltaic Cells". IEEE Proceedings on 35th Annual Power Electronics Specialists Conference, Aachen, Germany, 3, 1950-1956, 2004.

[15] Shekoofa O, Taherbaneh M. "Modelling of Silicon Solar Panel by MATLAB/Simulink and Evaluating the Importance of Its Parameters in a Space Application". Recent Advances in Space Technologies 3rd International Conference, İstanbul, Türkiye, 719-724, 14-16 June 2007.

[16] Yang SM, Lin FC, Chen MT. "Micro-Stepping Control of a Two-Phase Linear Stepping Motor with Three-Phase VSI Inverter for High-Speed Applications". IEEE Transactions on Industrial Applications, 40(5), 1257-1264, 2004.

[17] Chapman SJ. Elektrik Makinalarının Temelleri. Dördüncü Baskı, 2007.

[18] Türkyılmaz A. "RF Kontrol Işareti Kullanılarak Mikrodenetleyici Tabanlı Adım Motor Kontrol Setinin Hazırlanması". Yüksek Lisans Tezi, Marmara Üniversitesi Fen Bilimleri Enstitüsü, İstanbul, 2008. 